\title{
THE INCLUSION OF LESBIAN AND GAY POPULATIONS IN HEALTH RESEARCH: A SYSTEMATIC LITERATURE REVIEW
}

\begin{abstract}
This paper presents a systematic review of the literature and research conducted with the lesbian, gay and bisexual population in 10 years in the framework of health and mental health. A search in the Pubmed database for publications between 2001 and 2011 (inclusive) produced 404 articles. We firstly systematically mapped the empirical studies $(n=314)$ from among these articles and then did a detailed systematic literature review of those publications that are focused on health $(n=14)$. The analysis revealed that issues such as physical and sensory disabilities, sexual dysfunctions, and even the evaluation and integration of their sexual orientation in patients' sexual histories have been neglected.
\end{abstract}

Keywords: LG, health research, mental health research, systematic mapping, systematic review.

\begin{abstract}
Résumé
L'inclusion des populations gays et lesbiennes dans la recherche en santé: Une revue systématique de la littérature

Cet article présente une revue systématique de la littérature et des recherches menées auprès de la population lesbienne, gay et bisexuels en 10 dernières années dans le cadre de la santé et de la santé mentale. La recherche dans la base de données PubMed pour les publications entre 2001 et 2011 (inclus) produit 404 articles. Nous d'abord systématiquement cartographié les études empiriques $(n=314)$ parmi ces articles, puis fait un examen systématique de la littérature détaillée des publications de Qué sont axés sur la santé $(\mathrm{n}=14)$. L'analyse a révélé des problèmes de Qué tels que les handicaps physiques et sensoriels, troubles sexuels, et même de l'évaluation et de l'intégration de l'orientation sexuelle dans les histoires sexuelles de leurs patients ont été négligés.
\end{abstract}

Mots-clés: LG, recherche en santé, recherche en santé mentale, cartographie systématique, examen systématique.

\section{Resumen}

La inclusión de las poblaciones lesbianas y gay a la investigación en salud: una revisión sistemática de la literatura

Este trabajo pretende presentar una revisión sistemática de la literatura y la investigación llevada a cabo con la población de gays, lesbianas y bissexuales en los últimos 10 años en el cuidado de la salud. Una búsqueda en la base de datos PubMed (MEDLINE) para las publicaciones entre 2001 y 2011, 404 artículos fueron encontrados. En este estudio, primero realizamos una prospección sistemática de los estudios empíricos $(n=314)$ de estos artículos, y más tarde se llevó a cabo una revisión detallada sistemática de la literatura con los que se centró en el tema de la salud $(\mathrm{n}=14)$. El análisis reveló que estos temas vacíos como las discapacidades físicas o sensoriales, disfunción sexual e incluso la evalua- 
ción y la integración de la orientación sexual en la historia sexual de los pacientes, se han descuidado.

Palabras-clave: gay, lesbianas, salud, mapeo sistemático, revisión sistemática de la literatura.

\section{Introduction}

Despite the considerable amount of health studies over the past few years with the Lesbian, Gay and Bisexual (LGB) population, the approaches of homosexuality have not been systematic or comprehensive in many domains (Boehmer, 2002). The scientific literature has effectively focused on issues related to HIV and other sexually transmitted diseases, to the detriment of other, equally relevant aspects in this population, such psychological health and resilience, or LGB persons with congenital and/or acquired physical and/or sensory disabilities (Duke, 2011; Kuyper and Vanwesenbeeck, 2011).

The issues related to the LGB population's specific health and mental needs, as well as health care provision, have seldom been researched (Austin and Irwin, 2010). According to Marvin Goldfried (2001), mainstream literature has tended to ignore the work done in this area, neglecting issues such as social and family support, stigma and discrimination, suicidal ideation, substance abuse, and domestic violence. Aspects related to the implications of health inequalities and to minority populations' quality of life have also been overlooked (Makadon, 2011; Moleiro and Pinto, 2009; Mulé et al., 2009).

Goldfried (2001) points out that, despite professionals and researchers' interest in deepening understanding of these issues, this has not been translated into mainstream practice, hindering the access to the knowledge and to the desirable interconnections between LGB issues and mainstream psychology. It seems, therefore, important to systematise the information regarding the last decade of publications in the area of health and mental health with LGB populations, to promote their visibility and their mainstreaming.

In its initial phase this article seeks to promote a thematic overview of the research published with lesbian and gay population, resorting to this end to a systematic mapping study (Hemingway and Brereton, 2009). Its subsequent phase seeks to determine the main themes on which the articles focused on health converge, and what methodological resources are favoured in these studies.

\section{Method}

The systematic review of the literature (Khan, 2001) involved a search of the Pubmed (Medline) database with the following keywords: «gay», «lesbian», «sexual orientation», «homosexuality», and «sexual identity». In order to identify 
the empirical studies published in 10 years, we restricted the search to the period covering 2001 to 2011, inclusive, this being the only restriction applied.

Of the 404 articles found, two independent reviewers selected (as recommended by Hemingway and Brereton, 2009) 314 articles, which compose the sample in this study. This selection was done by reading the abstracts and applying the following exclusion criteria: (a) the abstract was not available $(n=39),(b)$ the articles were responses to already published articles $(n=3)$, and (c) the abstract made no reference whatsoever to the lesbian and gay population $(\mathrm{n}=48)$.

To provide an organised view of the research carried out on lesbian and gay health, the included articles were classified and quantified in thematic categories showing their research subject, as well as the theme emphasised most by the authors. This procedure used four types of pre-defined categories analysed in stages. The first coding stage determined the sexual orientation of the population studied. The second stage classified the articles according to the year of publication. The third, and final stage, divided the articles on the basis of their content according to two major themes: disease-specific content areas and non-diseasespecific content areas.

After analysing these 314 articles, 39 were identified that specifically addressed the theme of health. These articles, representing $12.7 \%$ of all the articles, were on mental health, physical health, health care, and psychotherapeutic services. For the subsequent analysis the following exclusion criteria were applied to these articles: (a) non-empirical articles (i.e., literature reviews or theoretical articles) $(n=25),(b)$ explored exclusively issues related to HIV/AIDS $(n=3)$, and (c) articles not written in English $(n=2)$. This methodological strategy resulted in the selection of 14 articles, whose full texts were carefully analysed, constituting the analytical material for the systematic review of articles focusing on health of lesbian and gay persons.

\section{Results}

Table 1 provides summary information regarding the first coding stage of the 314 articles that constitute the units of analysis. With regard to the first category, sexual orientation, we note that there is little difference in the number of studies using lesbian samples $(n=173)$ and those using gay samples $(n=171)$. No studies focusing exclusively on bisexual populations were found (i.e. they were included in the aforementioned categories). With regard year of publication, 174 articles (55.4\%) were coded as having been published from 2007 to 2011, inclusive, an increase of 10.8\% over the number published in 2001 to 2006, inclusive. 
Table $2 \mathrm{a}$ and $2 \mathrm{~b}$ summarises the codification according to the main themes or subject matter on which the analysis of the empirical studies published in the Pubmed (Medline) database in the last decade was based.

\section{Table 2a}

Distribution of articles by content areas $(\mathrm{N}=314)$

\begin{tabular}{llrrr}
\hline & Non-disease-specific content areas & $\mathbf{n}$ & \% \\
\hline \multirow{3}{*}{ Sexually transmitted disease } & Risky sexual behaviour & 11 & \\
& HIV and AIDS, including opportunistic infections & 11 & \\
& Sexually transmitted diseases other than AIDS & 2 & \\
& & Total & 24 & 7.6 \\
\hline \multirow{3}{*}{ Mental disorders } & Intellectual disability & 4 & \\
& Down syndrome & 1 & \\
& Mental illness, including personality disorder & 1 & \\
& & Total & 6 & 1.9 \\
\hline \multirow{3}{*}{ General health } & Physical health & & 1 & \\
& Mental health & 5 & \\
\hline \multirow{2}{*}{ Addiction behaviour } & & Total & 6 & 1.9 \\
\hline
\end{tabular}

Table $2 b$

Distribution of articles by content areas $(\mathrm{N}=314)$

\begin{tabular}{|c|c|c|c|c|}
\hline & & & n & $\%$ \\
\hline Identity, sexual & Identity, including gender or sexual identity & & 43 & \\
\hline \multirow[t]{10}{*}{ behaviour, or desire } & Relationship & & 5 & \\
\hline & Sexual behaviour & & 5 & \\
\hline & Coming out & & 4 & \\
\hline & Ageing & & 1 & \\
\hline & Physiology and body image & & 2 & \\
\hline & Attractiveness & & 7 & \\
\hline & Social support & & 2 & \\
\hline & Homophobia or heterosexism & & 8 & \\
\hline & Pornography & & 2 & \\
\hline & & Total & 79 & 25.2 \\
\hline \multirow[t]{5}{*}{ Exploration LG etiology } & Neuroscience or endocrinology & & 11 & \\
\hline & Genetics and birth order & & 10 & \\
\hline & History of homosexuality & & 6 & \\
\hline & Various others etiologic theories & & 9 & \\
\hline & & Total & 36 & 11.5 \\
\hline
\end{tabular}

1 More than 1 sexual orientation can be addressed in a single article. Therefore, the number of articles referring to lesbian and gay participants adds up to more than 314 and more than $100 \%$. 
Table $\mathbf{2 b}$ (cont.)

Distribution of articles by content areas $(\mathrm{N}=314)$

\begin{tabular}{|c|c|c|c|c|}
\hline \multicolumn{2}{|c|}{ Non-disease-specific content areas } & \multirow{2}{*}{\multicolumn{2}{|c|}{$\frac{\mathbf{n}}{7}$}} & \multirow[t]{2}{*}{$\%$} \\
\hline Attitudes and behaviour & Attitudes in educational institutions & & & \\
\hline \multirow[t]{8}{*}{ in society } & Images or stereotypes of LG persons & & 8 & \\
\hline & Change in attitudes toward LG persons & & 1 & \\
\hline & Discrimination and stigma & & 12 & \\
\hline & Rights and other legal aspects & & 5 & \\
\hline & Community and culture & & 17 & \\
\hline & Social networks & & 3 & \\
\hline & Sports & & 3 & \\
\hline & & Total & 56 & 17.8 \\
\hline \multirow[t]{3}{*}{ Health care } & Provider attitudes or patient-provider & & 7 & \\
\hline & Health needs and utilization & & 10 & \\
\hline & & Total & 17 & 5.4 \\
\hline \multirow[t]{6}{*}{ Psychotherapeutic services } & Guidelines for psychological practice & & 1 & \\
\hline & Psychiatry & & 1 & \\
\hline & Psychotherapy & & 6 & \\
\hline & Psychoanalysis & & 4 & \\
\hline & Conversion therapies & & 3 & \\
\hline & & Total & 15 & 4.8 \\
\hline \multirow[t]{8}{*}{ Risk factors } & Risky health behaviour & & 2 & \\
\hline & Suicide thoughts & & 6 & \\
\hline & Prostitution & & 1 & \\
\hline & Stress due to minority status & & 3 & \\
\hline & Sexual abuse & & 3 & \\
\hline & Domestic violence & & 1 & \\
\hline & Various forms of violence & & 2 & \\
\hline & & Total & 18 & 5.7 \\
\hline \multirow[t]{4}{*}{ Family } & Parenting & & 14 & \\
\hline & Reproduction & & 0 & \\
\hline & Adoption & & 1 & \\
\hline & & Total & 15 & 4.8 \\
\hline \multirow[t]{5}{*}{ Miscellaneous topics } & Freudian theory & & 1 & \\
\hline & Religion or church & & 7 & \\
\hline & Articles on singular topic & & 8 & \\
\hline & Scale & & 11 & \\
\hline & & Total & 27 & 8.6 \\
\hline
\end{tabular}




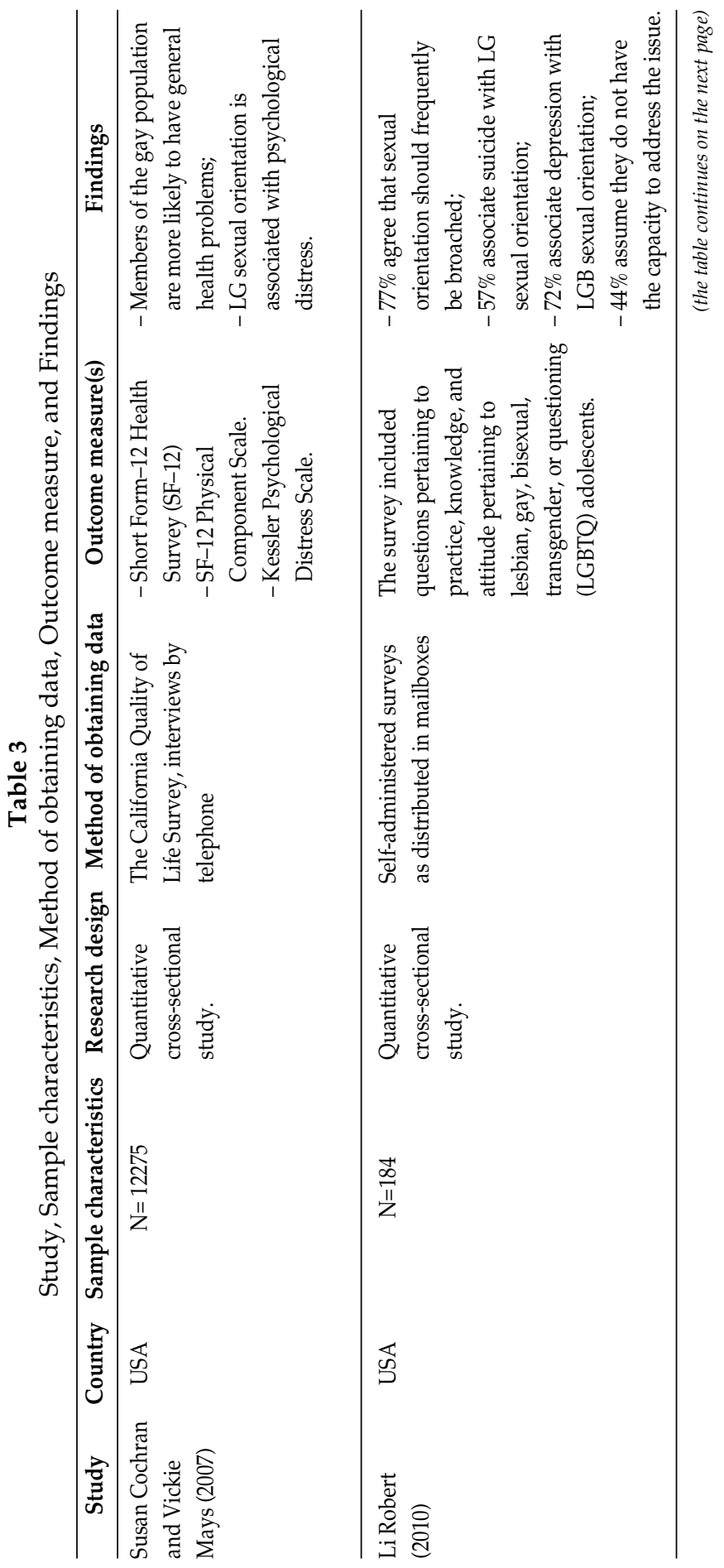

ex æquo, n.ㅇ 32, 2015, pp. 169-182 


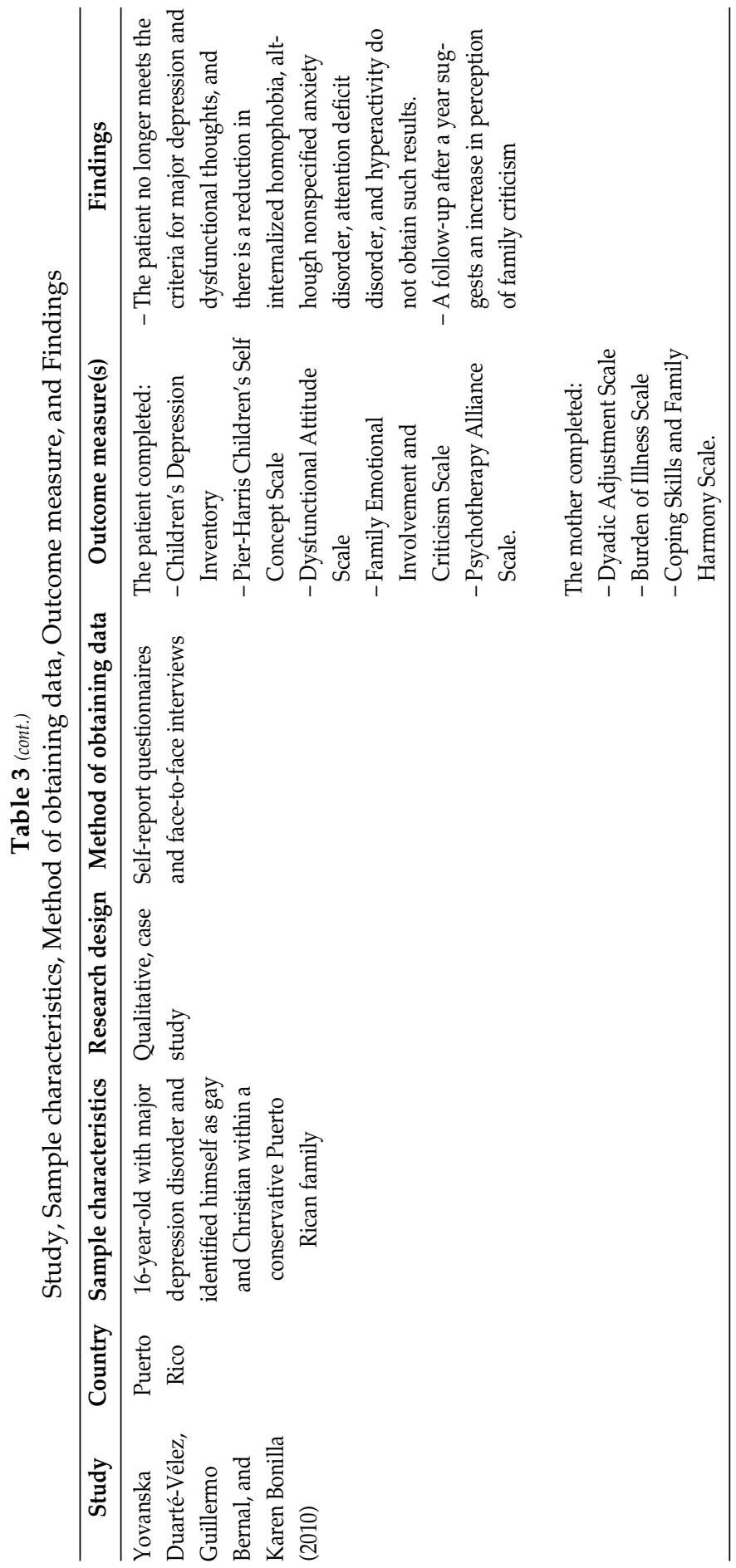

ex æquo, n.. 32, 2015, pp. 169-182 


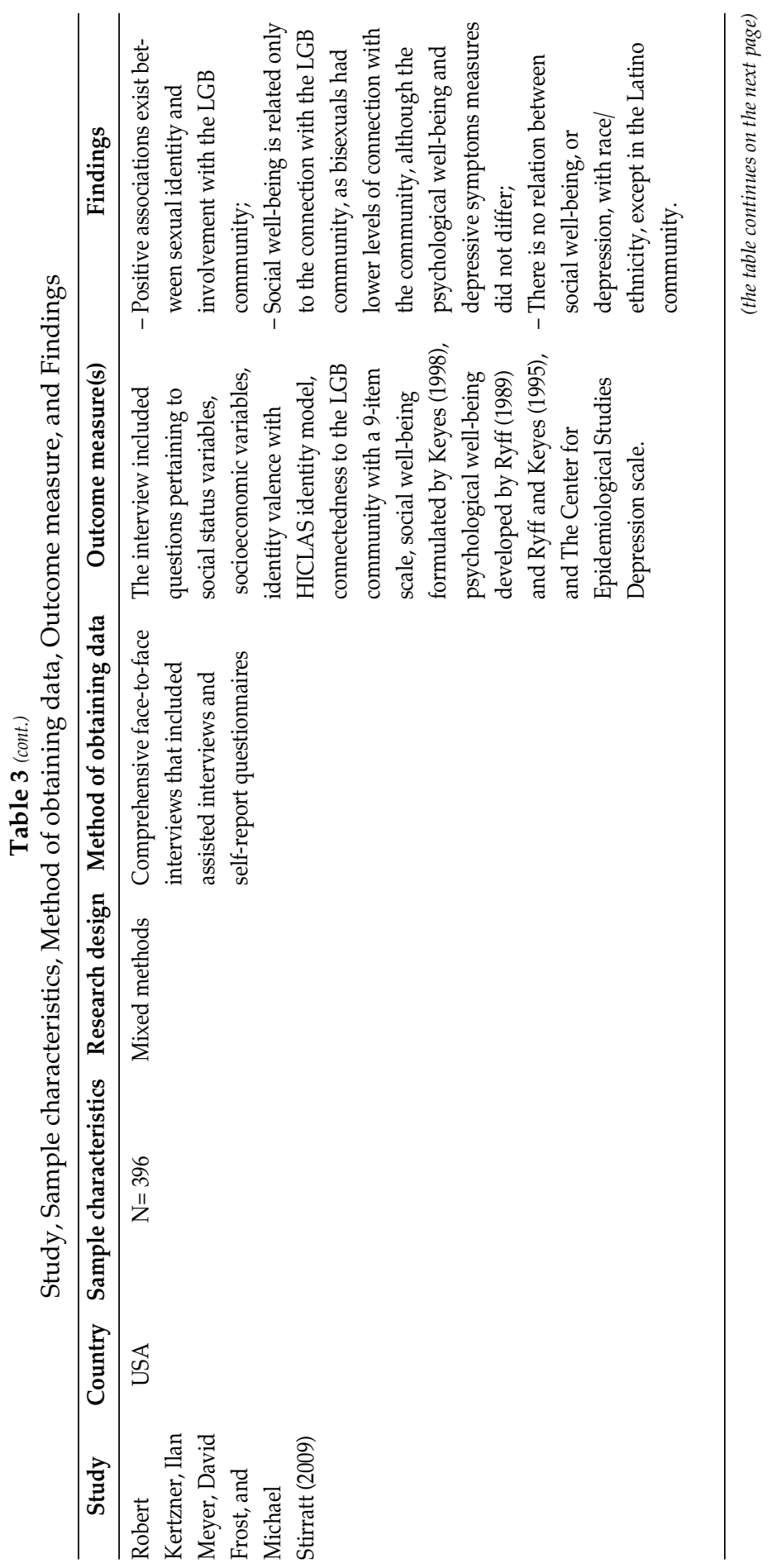

ex æquo, n.․3 32, 2015, pp. 169-182 


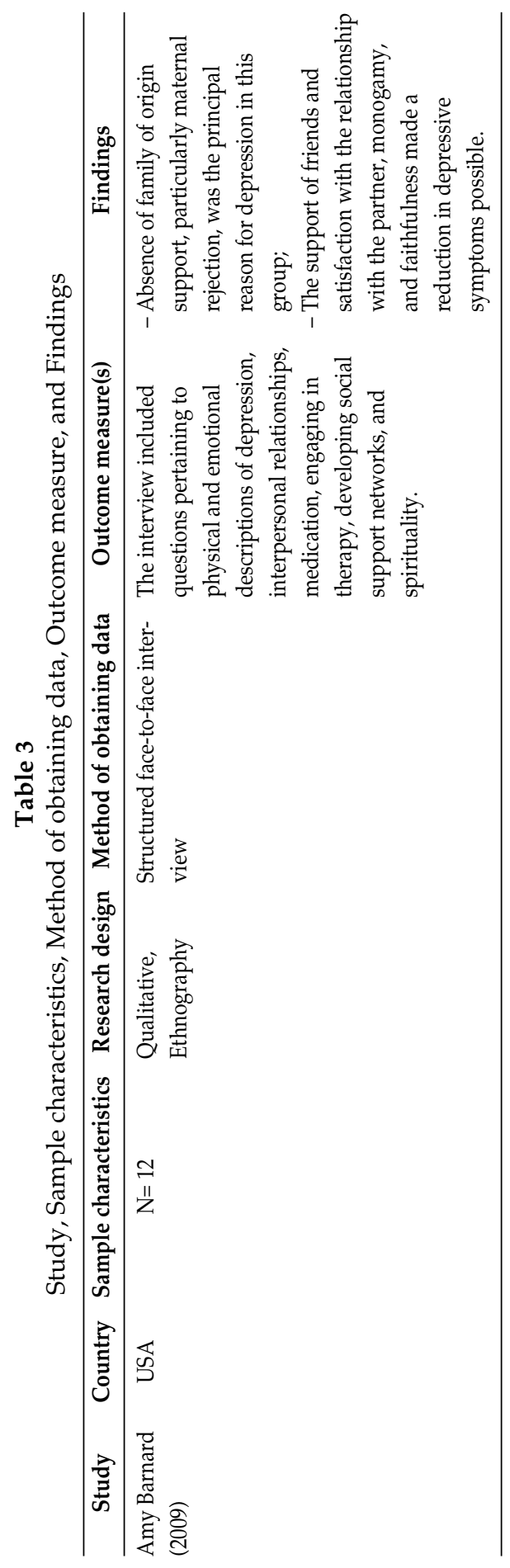

ex æquo, n. 32 , 2015, pp. 169-182 
After analysing the 314 articles found, 39 articles focused on health of lesbian and gay individuals. According to what has been described in the method section, only 14 articles, which focused on LG health, were selected for the detailed systematic review (Table 3).

Most of the research that makes up this group was produced in the United States of America $(n=9)$. The other authors were from New Zealand $(n=2)$, Puerto Rico $(n=1)$, Canada $(n=1)$, and Sweden $(n=1)$.

Of the 14 articles analysed in this review, 6 articles used quantitative methodology, 5 qualitative methodology, and 3 mixed methods. Of the 6 quantitative articles, 4 were cross-sectional studies with convenience samples, and only one was a national survey. The results also suggested that most of the qualitative articles had an ethnological perspective $(n=4)$, while one article chose the case study method and another the Delphi method. Here again the convenience or network sampling methods were the most common. With regard to the instruments, articles were found that used purpose-built questionnaires $(n=4)$, semi-structured interviews $(n=4)$, clinical vignettes $(n=1)$, psychological assessment instruments $(n=1)$, and a Delphi Questionnaire $(n=1)$. There were also 3 articles that used both semi-structured interviews and purpose-built questionnaires.

Most of the articles in this systematic literature review identified the participants' sexual orientation $(n=11)$. The remaining articles $(n=3)$ did not, given that their samples were composed of experts: one General Practitioners, another Psychologists, and in another specialists in various fields of knowledge, namely Family Therapists, Psychologists, Social Workers, Psychiatrists, and Professional Counselors.

\section{Discussion}

This article sought to show the diversity of themes developed by the scientific community on health with lesbian and gay participants in the last 10 years. According to the results of this systematic literature review, the theme with the largest number of articles was identity, including gender or sexual identity, which occupied second place in Boehmer's (2002) systematic survey. This identity theme was the focus of analysis of most research in the seventies and eighties. While these studies are still considered important today (Nunan, 2003), controversy and debate still exist, questioning the classic notions of self and identity, as well as the homo/heterosexual dichotomy or fluidity.

The theme LGB Community and culture was found to be the second-largest category of articles. These results are consistent with the literature that emphasises the link of lesbian and gay people with the community and its role on the reduction of internalised homophobia, reducing the risks of stigmatisation, prejudice, and discrimination, thereby promoting personal and social 
well-being, reiterating the theoretical assumptions of David Frost and Ilan Meyer (2012).

A more controversial theme, the aetiology of homosexuality, was found in third place. By contrast, the absence of research exploring the aetiology of heterosexuality suggests a psychopathologisation by the health professionals themselves (Moleiro and Pinto, 2009), even if often subtly, and occasionally more blatantly. This result is meaningful in the context of recent surveys of psychotherapist (e.g. in the U.K.) who still favour of use of conversion therapies and other sexual orientation change efforts, also found in this review (Moleiro and Pinto, 2009). These findings, however, seem to be in clear contradiction to the APA's affirmation that "same-sex sexual attractions, behavior, and orientations per se are normal and positive variants of human sexuality-in other words, they do not indicate either mental or developmental disorders» (APA, 2009: 2), and hence do not warrant specific explaining. They also collide with APA's support of affirmative multicultural treatments, and recognition of lack of support of interventions to change sexual orientation due to insufficient evidence (APA, 2009).

The literature review also suggests that, although methodological changes have been observed in research on sexual minorities (Plummer, 2011), on the whole homosexuality has continued to be theorised about in scientific literature in the last decade (Hunt, Matthews, Milson, and Lammel, 2006). This was evidenced by the exclusion of 25 articles through including the criterion «non-empirical article (i.e., literature reviews or theoretical articles)».

It should be noted that the results of the present study show the paucity and even absence of scientific production on some themes, such as issues related to adoption, reproduction, domestic violence, sexual dysfunction, and physical and sensory disabilities (Duke, 2011; Kuyper and Vanwesenbeeck, 2011).

The articles in the literature review in the specific realm of health point toward the conclusion that most health professionals have neither the technical nor the theoretical knowledge or the specific skills to work with people from minority groups, such as lesbian and gay people (Dunn and Abulu, 2010). The articles also indicated that health professionals consider heterosexuality as the norm for sexual orientation and neglected sexual health, sexual orientation, and sexual identity in the clinical process, as Naseer Haboubi and Nadina Lincoln (2003) have already described. These findings highlight research gaps and can reinforce the particularities of work with and of the care of lesbian and gay people in the health context, and considers the qualifications, the specific training, and the supervision of these professionals to be fundamental (Makadon, 2011; Moleiro and Pinto, 2009).

Finally, it is important to note that more than half of the studies in this literature review were done in the USA, which, following Cara Booker, Seeromanie Harding, and Michaela Benzeval (2011), makes it difficult to generalise the results, not only because of the cultural differences, but also the different subsamples of the gay and lesbian population. 


\section{Conclusion}

One of the most interesting and relevant results of this study, and of the research with non-heterosexual population on health in the decade studied, seems to be related to the identification of lacunae in a series of domains. This was evident by the absence of publications addressing themes such as adoption, reproduction, domestic violence, sexual dysfunction, and physical or sensory disabilities. This illustrates the need for more research addressing these themes among this population, highlighting its diversity.

The invisibility of issues relating to sexual orientation on health practices and the imposition of heteronormativity, with implications for the care and treatment of lesbian and gay patients, are also noteworthy. The results also show the shortage of health professionals' specific skills and training in serving the lesbian and gay clients. Hence, there seems to be a need for continued deepening of the knowledge of this population, integrating this into universities' undergraduate and postgraduate programs as well as in training programs (Makadon, 2011; Moleiro and Pinto, 2009). This is in line with the guidelines for psychological interventions with sexual minorities, developed and updated by the APA (2011), in order to improve lesbian and gay clients' quality of life (World Health Organization, 2011).

The present study's limitations lie in the use of a single database and the exclusion of keywords such as «bisexual», "bisexuality», «men who have sex with men, men who have sex with men and women», «queer», «pansexual», «two-spirited» or «butch/femme». These aspects may have contributed towards limited interpretations of the results and difficulties in determining the existence of an advance in knowledge in this area. Future studies should aim to encompass various databases, in order to provide a specific view of the central, most studied categories, as well as the methodology used to this end, thereby contributing towards a greater understanding of the panorama of scientific production on this theme. In addition, the time frame of the search could be extended in order to ascertain the evolution of studies on the theme of homosexuality across time, particularly on health and, consequently, to establish the existence of a convergent pattern of intervention.

\section{References}

American Psychological Association (2011), Practice guidelines for LGB clients: guidelines for psychological practice with lesbian, gay, and bisexual clients, American Psychological Association, [online] availabe at www.apa.org/pi/lgbt/resources/guidelines.aspx [retrieved on 15/01/2011].

American Psychological Association (2009), Report of the American Psychological Association Task Force on Appropriate Therapeutic Responses to Sexual Orientation, American Psychological Association, [online] availabe at http://www.apa.org/pi/lgbt/resour ces/therapeutic-response.pdf [retrieved on [15/01/2011]. 
Austin, Erika; Irwin, Jay (2010), «Health Behaviors and Health Care Utilization of Southern Lesbians», Women's Health Issues 20, 178-184.

Barnard, Amy (2009), «Lesbians' Constructions of Depression», Health Care for Women International 30(5), 373-389.

Boehmer, Ulrike (2002), «Twenty Years of Public Health Research Inclusion of Lesbian, Gay, Bisexual, and Transgender Populations», American Journal of Public Health 92(7), 1225-1230.

Booker, Cara; Harding, Seeromanie; Benzeval, Michaela (2011), "A systematic review of the effect of retention methods in population-based cohort studies», BMC Public Health 11, 249-260.

Cochran, Susan; Mays, Vickie (2007), «Physical Health Complaints among Lesbians, Gay Men, and Bisexual and Homosexually Experienced Heterosexual Individuals: Results From the California Quality of Life Survey», American Journal of Public Health 97(11), 2048-2055.

Duarté-Vélez, Yovanska; Bernal, Guillermo; Bonilla, Karen (2010), «Culturally adapted cognitive-behavior therapy: integrating sexual, spiritual, and family identities in an evidence-based treatment of a depressed Latino adolescent», Journal of Clinical Psychology 66(8), 895-906.

Duke, Thomas (2011), «Lesbian, Gay, Bisexual, and Transgender Youth with Disabilities: A Meta-Synthesis», Journal of LGBT Youth 8(1), 1-52.

Dunn, Marian; Abulu, John (2010), «Psychiatrists' Role in Teaching Human Sexuality», Academic Psychiatry 34(5), 381-385.

Frost, David; Meyer, Ilan (2012), «Measuring Community Connectedness among Diverse Sexual Minority Populations», Journal of Sex Research 49(1), 36-49.

Goldfried, Marvin (2001), «Integrating lesbian, gay, and bisexual issues into mainstream psychology», American Psychologist 56, 977-988.

Haboubi, Naseer; Lincoln, Nadina (2003), "Views of health professionals on discussing sexual issues with patients», Disability and Rehabilitation 25, 291-296.

Hemingway, Pippa; Brereton, Nic (2009), What is a systematic review? What is...? series Haywood Medical Communications, [online] availabe at http://www.medicine.ox.ac.uk/ bandolier/painres/download/whatis/Syst-review.pdf [retrieved on 23/12/2011].

Hunt, Brandon; Matthews, Connie; Milsom, Amy; Lammel, Julie (2006), «Lesbians with physical disabilities: A qualitative study of their experiences in counselling», Journal of Counseling and Development 84, 163-173.

Kertzner, Robert; Meyer, Ilan; Frost, David; Stirratt, Michael (2009), «Social and psychological well-being in lesbians, gay men, and bisexuals: the effects of race, gender, age, and sexual identity», American Journal of Orthopsychiatry 79(4), 500-510.

Khan, Khalid (2001), Undertaking Systematic Reviews of Research on Effectiveness: CRD's Guidance for those Carrying Out or Commissioning Reviews, NHS Centre for Reviews and Dissemination, University of York.

Kuyper, Lisette e Vanwesenbeeck, Ine (2011), «Examining Sexual Health Differences between Lesbian, Gay, Bisexual, and Heterosexual Adults: The Role of sociodemographics», Sexual Behavior Characteristics, and Minority Stress. Journal of Sex Research 48(2-3), 263-274.

Makadon, Harvey (2011), «Ending LGBT invisibility in health care: the first step in ensuring equitable care», Cleveland Clinic Journal of Medicine 78, 220-224.

Moleiro, Carla; Pinto, Nuno (2009), «Diversidade e psicoterapia: expectativas e experiências de pessoas LGBT acerca das competências multiculturais de psicoterapeutas», ex aequo 20, 159-172. 
Mulé, Nick et al. (2009), «Promoting LGBT health and wellbeing through inclusive policy development», International Journal for Equity in Health 8, 18.

Nunan, Adriana (2003), Homossexualidade: do preconceito aos padrões de consumo, Rio de Janeiro, Caravansarai.

Plummer, Ken (2011) «Critical humanism and queer theory. Living with tension», in Norman Denzin; Yvonna Lincoln (Org.), The Sage Handbook of Qualitative Research, Thousand Oaks, Sage, 195-207.

Robert, Li (2010), «Barriers to Optimal Care between Physicians and Lesbian, Gay, Bisexual, Transgender, and Questioning Adolescent Patients», Journal of Homosexuality 57(6), 730-747.

Tjepkema, Michael (2008), «Health care use among gay, lesbian and bisexual Canadians», Health Reports 19(1), 53-64.

World Health Organization (2011), Guiding Principles for National Health Workforce Strategies. Global Health Workforce Alliance, [online] availabe at http://www.who.int/ healthsystems/round9 6.pdf [retrieved on 23/11/2011].

Mónica José Abreu Sousa. MSc. in Psychology.

Monic4sous4@gmail.com

Carla Moleiro. Ph.D. in Clinical Psychology. Assistant Professor at the Lisbon University Institute ISCTE-IUL / CIS-IUL, Department of Social and Organizational Psychology; School for Social Sciences and Humanities.

carla.moleiro@iscte.pt

Correspondence Address: Carla Moleiro - Department of Social and Organizational Psychology - ISCTE-IUL (box 310). Avenida das Forças Armadas, 1649-026 Lisbon, Portugal. carla.moleiro@iscte.pt, phone: +351 21790 3216; fax: +351 217964710.

Artigo recebido em 30 de julho de 2014 e aceite para publicação em 22 de outubro de 2014. 